\title{
A Framework for Interpreting Lateral Swelling Pressure in Unsaturated Expansive Soils
}

\author{
Mingyu Li $\mathbb{D}^{1},{ }^{1}$ Yanqing Wei $\mathbb{D}^{1,2}$ Yunlong Liu ${ }^{10},{ }^{1}$ and Junwei Jin $\mathbb{I D}^{1}$ \\ ${ }^{1}$ School of Civil Engineering, Zhengzhou University, Zhengzhou 450001, China \\ ${ }^{2}$ School of Civil Engineering, Luoyang Institute of Science and Technology, Luoyang 471000, China \\ Correspondence should be addressed to Yunlong Liu; liuyunlongzzu@hotmail.com
}

Received 30 October 2020; Revised 22 December 2020; Accepted 20 January 2021; Published 3 February 2021

Academic Editor: Yinshan Tang

Copyright (c) 2021 Mingyu Li et al. This is an open access article distributed under the Creative Commons Attribution License, which permits unrestricted use, distribution, and reproduction in any medium, provided the original work is properly cited.

Lateral swelling pressure (LSP) develops when expansive soil volume increment associated with water infiltration is restrained in a confined domain, for example, due to construction of civil infrastructure. In this paper, initially a flowchart is developed to highlight various key factors that influence the LSP mobilization according to lab and field studies collected from previous literature studies. Then extending unsaturated soil mechanics, a theoretical framework is proposed for illustrating the LSP mobilization in the field against retaining structures and pile foundations under different boundary conditions, respectively. An example problem for a basement wall and a pile foundation constructed in a typical expansive soil from Regina, Canada, is presented to illustrate the proposed theoretical framework. The framework and corresponding analysis presented in this paper can facilitate to provide rational designs of geotechnical infrastructures in expansive soils.

\section{Introduction and Background}

Expansive soil that is susceptible to volume increases or decreases, respectively, with changes in water content offers challenges to geotechnical engineers in the rational design of geotechnical infrastructures. Typically, an additional reaction pressure generates on the infrastructure if the volume expansion associated with water infiltration is restricted. For this reason, design and construction of infrastructure in regions with expansive soils, which are widely distributed all over the world, should be given special consideration taking account of this additional reaction pressure.

Horizontal deformation in expansive soils that arises due to water infiltration, if restricted, results in the development of lateral swelling pressure (LSP) and acts on the infrastructure in addition to the lateral earth pressure (LEP) that is typically associated with soil self-weight and/or surcharge. LSP effects are common on retaining structures (for example, retaining walls and cantilever sheet pile walls) with expansive soils as backfill and other infrastructure constructed within expansive soils (for example, basements, sewer lines, pipelines, and deep foundations). In several scenarios, LSP can have significant influences on the infrastructure stability and safety. Generally for fixed retaining structures (at-rest condition), the LEP is less than the vertical pressure (i.e., overburden pressure and surcharge effects), while, in an investigation study conducted by Richards and Kurzeme [1], the measured LEP considering the influence of LSP behind a $7.5 \mathrm{~m}$ retaining wall was found to be 1.3 to 5.0 times the overburden pressure. Lytton [2] summarized various case histories available in the literature to quantify LSP and suggested that the LEP acting on retaining structures considering LSP can be approximately four times the overburden pressure value. Moza et al. [3], from their investigations, suggested that LSP value in certain scenarios could be greater than ten times the overburden pressure value. Joshi and Katti [4] conducted a large-scale model test and measured the LSP at a depth of $0.28 \mathrm{~m}$, which was ten times greater than the vertical swelling pressure. More recently, Mohamed et al. [5] monitored the LSP behind a basement wall and suggested that its value can be seven times the LEP value assuming active conditions.

Problems associated with the LSP of expansive soils received significant research attention over the past several 
decades [6-10]. Both laboratory and in situ techniques are available for the determination of the LSP. Several investigators have proposed experimental methods to determine the lateral LSP introducing modifications to the traditional odometer and hydraulic triaxial apparatus [11-14]. Largescale tests and in situ investigations were also undertaken to determine the LEP considering influence of the LSP and understand its influence on the infrastructures $[15,16]$. However, these tests are generally complex and require assistance of trained professional services which are expensive and hence cannot be used in routine engineering practice. Also, due to the low hydraulic conductivity of expansive soil, they are usually time-consuming.

Considering various difficulties encountered in the lab and field testing of LSP as discussed above, in this paper, initially key influencing factors which determine the LSP mobilization is summarized through a flowchart, and then a simple theoretical framework is proposed extending unsaturated soil mechanics which is capable of providing reliable prediction of LEP considering LSP against fixed rigid retaining structures after a matric suction increment. An example problem which simulates a rigid basement wall and a pile in a typical expansive soil-Regina clay-is introduced to illustrate the application of the proposed theoretical framework. The flowchart and theoretical framework can be valuable for the practicing engineers to address the challenges associated with the design and construction of infrastructure in expansive soils.

\section{Various Factors Determining the Mobilization of LSP}

Based on the comprehensive investigations of the published experimental results, various factors that influence the mobilization of LSP are summarized in a flowchart, as shown in Figure 1.

\section{Various Factors That Influence Swelling Potential}

The swelling potential of an expansive soil is stored within the soil mass as an internal stress. This potential is dependent on the clay minerals present within the structure of the expansive soil. Montmorillonite and Illite are two key clay minerals that contribute to the swelling behavior in expansive soils. The percentage of the clay minerals present within expansive soil provides valuable information about the swelling potential. Swelling potential of an expansive soil increases with an increase in the clay content (i.e., clay fraction whose size is $2 \mathrm{~mm}$ or less). The swelling potential within an expansive soil can be empirically estimated from its initial water content and dry density $[17,18]$. High dry density and low initial water content usually signifies a high swelling potential within an expansive soil. This is because higher density soils are associated with a larger clay fraction in a certain volume while low initial water content soil has the ability to imbibe more moisture into soil pores contributing to the soil swelling. For remoulded soils, these two factors are dependent on the degree of compaction condition (i.e., compaction energy), which in turn has a significant influence on the expansive soil structure. Soils compacted at dryness of optimum water content have flocculated structure with random particle orientation (i.e., flocculated structure). However, soils compacted with water contents greater than optimum moisture content typically have their soil particles mostly oriented parallel to each other due to dispersed structure. Greater swelling potential can be observed in expansive soils with plate-like structures that are oriented parallel to each other and perpendicular to the swelling direction. Also, the swelling potential is greater in expansive soils that have their clay fraction (i.e., montmorillonite) particles parallel to the direction of compaction. For natural expansive soils which show strong anisotropic behavior, the swelling potential in the vertical direction is usually greater than lateral (horizontal) direction for a flatlying deposit; however, for steeply dipping deposit, it is just the opposite [19].

\section{Water Infiltration as the Triggers}

The swelling potential is a stored energy that is released when water intrusion occurs within an expansive soil. In the laboratory, moisture migration inside the soil specimen can be mainly attributed to thermal, capillary, and osmosis action. However, in the field, moisture variation is associated with many factors such as the precipitation, ground water table variation, lawn irrigation, and leakage of underground pipes lines. Influence of environmental factors along with the nonuniform soil profile that is commonly encountered in engineering practice makes the problem far more complex. Expansive soil problems can be predominantly attributed to the water content changes in the soil layer that is close to natural ground surface, with deep-seated heave being rare [20]. These layers are usually referred to as zone of seasonal fluctuations or, simply, active zone. Nelson et al. [21] summarized two key characteristics for the active zone in expansive soils. The first characteristic is associated with significant matric suction variation that occurs in the active zone depth; and the second characteristic is related to the heave that is predominant again in this zone. Estabragh et al. [22] suggested that the swelling behavior of expansive soil is also influenced by the type of wetting fluids: acidic water and saline water reduce the swelling potential of compacted soil while reduction in salt concentration of wetting fluids enhances the swelling potential.

\section{Influence of Stress Path on the LSP Mobilization in Lab Test}

The laboratory methods used in the measurement of swelling pressure are stress path dependent. Soil specimens tested using different methods that follow different stress paths provide varying results, in spite of undergoing the same amount of volume change during the testing process. Results to support these conclusions were derived from vertical swelling pressure measurement methods using oedometers by several investigators [23]. Three methods are widely used [24] for vertical swelling pressure measurements, which 


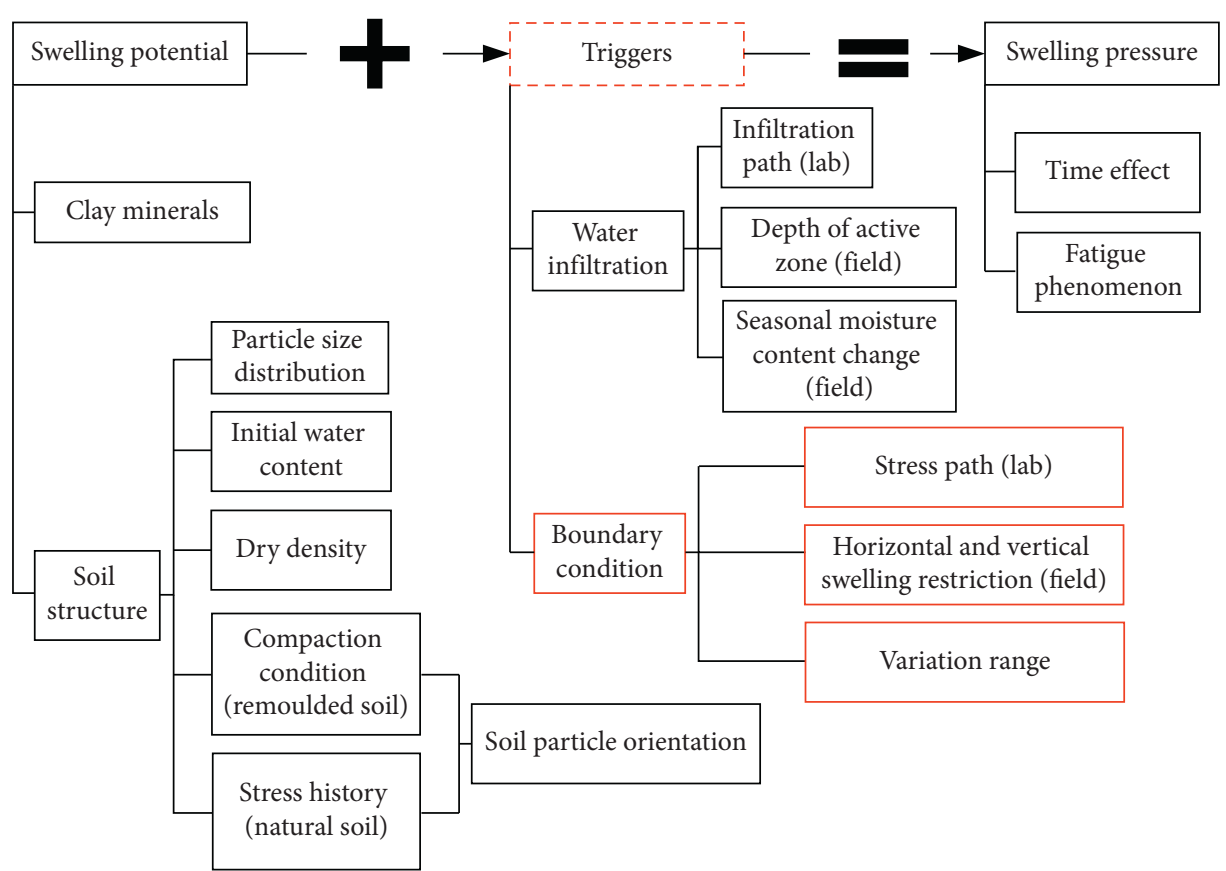

FIgUre 1: A flowchart illustrating key factors that contribute to the mobilization of LSP.

include the constant volume method, swell and load back method, and swell under surcharge method. A typical expansive soil specimen tested in modified oedometer has a stack of lattice layers that are interconnected by up to four layers of crystalline water composing a clay particle $(2: 1$ tetrahedral-octahedral-tetrahedral sandwich layer of clay mineral crystals). Then, an assembly of clay particles denoted as the clay aggregate forms the unit of the compacted clay double structure. An assembly of aggregates from the macrostructure and the voids between the aggregates are denoted as macrovoids [25]. The volume expansion of expansive soil can be attributed to the increasing amount of water intruding into these three level structures, namely, lattice layer, clay particles, and clay aggregates. The first level constitutes the crystalline water that exists between lattice layers within the clay particle. The amount of crystalline water present mainly depends on the matric suction forces [26] and is sensitive to chemical properties of the pore water [27]. The second level is the double-layer water that surrounds individual clay particle in the diffuse double layer. The size (amount) of diffuse double layer depends on the ion concentration in the equilibrium solution to be directly related to osmotic suction $[26,28]$. The third level is the macropore among clay aggregates. The double-layer water gradually becomes equilibrium water as the distance from clay particles increases. The amount of equilibrium water inside the soil specimen is related to matric suction while the volume of macropores determines the total amount of equilibrium water that can be stored in the test specimen.

In the oedometer test, prior to water infiltration (see Figure 2(a)), macropores inside the unsaturated soil specimen are partially filled with water that are under a state of equilibrium condition. Limited amount of double-layer water and crystalline water is bound to the cation cloud that forms on the clay particle surface and inside the interlayer space of clay particles, respectively. Upon saturation, the changes within the pore water chemical properties and solution concentration for soil specimens tested using three different methods are almost the same. For this reason, the amount of crystalline water and double-layer water gain is almost the same. In other words, clay aggregates inside these specimens undergo similar expansion. However, for soil specimen tested using constant volume condition (see Figure 2(b)), during saturation, the volume expansion is restricted by fixed vertical boundary (void ratio $e$ is constant). Structure changes arise due to enlarged clay aggregates during the swelling process. However, in the swell and load back test (shown in Figure 2(c)), significant changes occur in the structure that generates more macropores during saturation of the soil specimen. During the consolidation process, the excess pore water pressure is released and the vertical swelling pressure is expressed as a function of effective stress (see Figure 2(d)). Soil structure changes occur mainly during the consolidation process. As for the constant consolidation pressure test, prior to water infiltration, the soil specimen first consolidates under the applied surcharge (as shown in Figures 2(e) and 2(f)). In other words, soil structure changes occur both in the consolidation and during the swelling process. In spite of the final volume of soil specimen being the same using the different testing methods, the differences in arrangement and structure of clay aggregates contribute to differences in the measured values of swelling pressures. Several researchers investigations suggest that the vertical swelling pressure measurement from constant volume test falls between the swell and load back test (which is typically the largest) and constant consolidation pressure test (which is the lowest) (for example, [29]). Modifications were introduced into the 


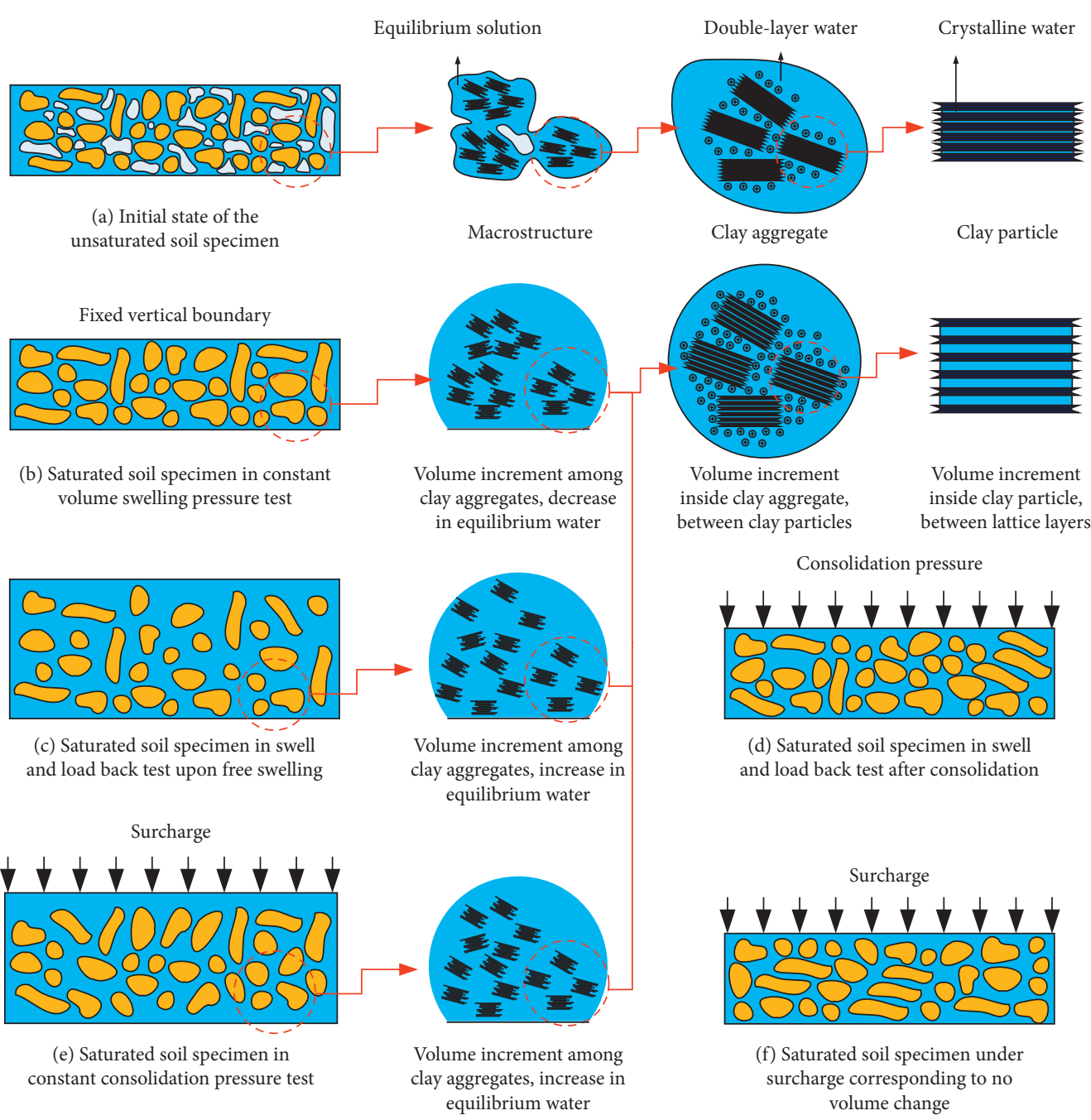

FIgURE 2: Structure changes that arise in the soil specimens upon saturation in different swelling pressure measurement tests.

traditional oedometers with the objective for measuring the LSP simultaneously along with the vertical swelling pressure measurement. Among the three stress paths introduced above, the swell under surcharge test is the widely accepted method for the measurement of LSP because it well simulates the scenario that is typically encountered in engineering practice. As discussed earlier, in this test, the soil specimen swells under a surcharge load that is representative to overburden pressure associated with self-weight of upper layer soil and/or load from the superstructure.

\section{Influence of Boundary Effect on LSP Mobilization in the Field}

Two key points should be given due consideration in understanding the influence of boundary conditions on the LSP that arises typically in expansive soils. The first one is related to the significant reduction in the swelling pressure by allowing a limited strain in expansive soils [30]. Geotechnical engineers typically extend this approach in practice to reduce the LSP acting on retaining works [31-33]. The second point is the mobilization of LSP and the ground heave, which are interrelated [34]. The LSP decreases with an increase in the ground heave. For example, in intact expansive soils, volume strain predominantly occurs in the vertical direction contributing to ground heave. However, if there are significant fissures within the expansive soils, larger portion of volume strain will occur laterally instead of vertical direction; due to this reason, there will be limited ground heave.

The LSP mobilization is influenced by both horizontal and vertical stress boundary conditions. Liu and Vanapalli [35] presented a detailed discussion on the influences of horizontal volume restriction on the mobilization of LSP. Furthermore, a theoretical model was also proposed for the calculation of LEP considering LSP [35]. In this paper, influences of vertical stress boundary conditions on the mobilization of LSP are analyzed and summarized in the following sections.

Figure 3(a) shows a fixed retaining wall constructed with expansive soil as backfill material and Figure 3(b) shows a pile that is buried in an expansive soil with no crawl set space on the top. During seasonal wetting and drying cycles, expansive soil behavior against the retaining wall and the 


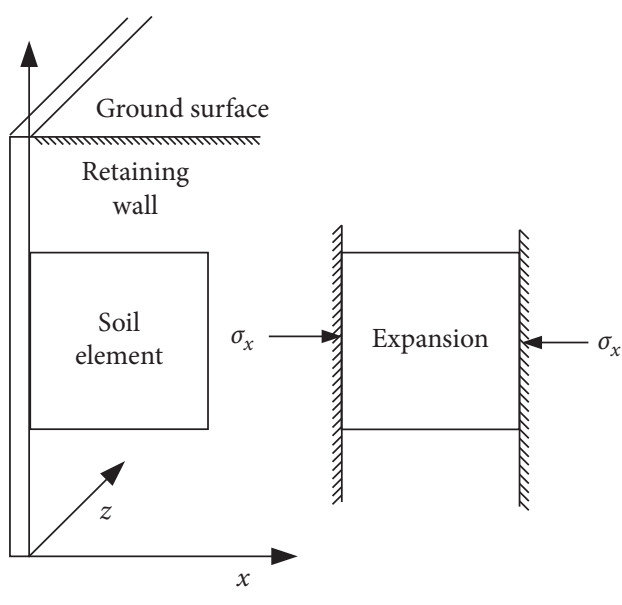

(a)

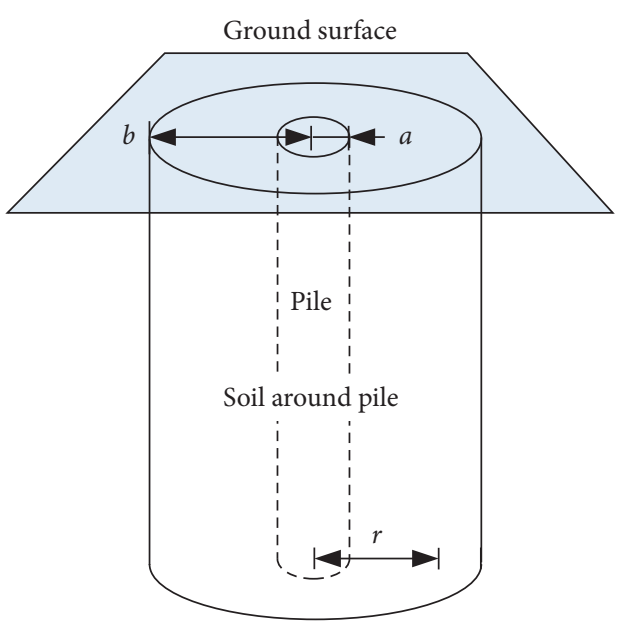

(b)

Figure 3: Mobilization of LSP. (a) Against retaining wall and (b) around the pile.

pile can experience significant variation. The LEP changes for both scenarios associated with the suction changes are analyzed and discussed in this section.

For a fixed retaining wall, the strain in $z$ direction can be neglected, if the length is assumed infinite or extensively long. A square soil element within the cross section as shown in Figure 3(a) can be simplified as a plane strain problem. With a decrease in matric suction, the soil element has a tendency to expand in both $x$ and $y$ directions. Assuming expansion in $x$ direction is restricted due to the influence of boundary condition and in $y$ direction expansion is influenced by a vertical stress (i.e., due to soil self-weight and/or surcharge), the relationship between the decreased matric suction and the horizontal stress discussed for the above typical scenario can be expressed using equation (1). In equation (1), (a) is suitable for scenarios for unsaturated expansive soils while (b) is suitable for scenarios in expansive soil that have attained saturated condition after wetting. It should be noted that (1)(a) is just the net horizontal stress written in terms of the vertical stress for the at-rest or $K_{0}$ condition in an intact, homogeneous, unsaturated soil mass assuming the strain in the horizontal directions equals zero, as given in Fredlund and Rahardjo [36].

$$
\sigma_{h}=\left\{\begin{array}{l}
\sigma_{x}-u_{a}=K_{0} \sigma_{s}-\frac{\Delta\left(u_{a}-u_{w}\right) E}{(1-v) H} \quad(\mathrm{a}), \\
\sigma_{x}-u_{a}=K_{0} \sigma_{s}^{\prime}-\frac{\Delta\left(u_{a}-u_{w}\right) E}{(1-v) H}+u_{w} \quad(\mathrm{~b}),
\end{array}\right.
$$

where $K_{0}$ is coefficient of at-rest earth pressure; $K_{0} \approx 1-\sin \phi^{\prime}$ for normally consolidated soil; $K_{0} \approx\left(1-\sin \phi^{\prime}\right) \mathrm{OCR}^{\sin \phi^{\prime}}$ for over consolidated soil; $\phi^{\prime}$ is the effective internal friction angle of soil; OCR is overconsolidation ratio; $\sigma_{s}^{\prime}$ is effective vertical stress, $\sigma_{s}$ is total vertical stress; $u_{w}$ is pore water pressure; $E$ is elastic modulus with respect to net normal stress; $H$ is elastic modulus with respect to matric suction; and $\Delta\left(u_{a}-u_{w}\right)$ is matric suction variation.
For piles placed in expansive soils, the soil around the pile can be assumed as a hollow cylinder with inner diameter $a$ and external diameter $b$ ( $b$ is infinite). With a decrease in matric suction, the hollow cylinder tends to expand in both axial and radial directions. However, fixed boundary conditions restrict both the inner and external expansion. Assuming there is no crawl spacing between the ground surface and the foundation to accommodate the possible ground heave, the vertical expansion of the soil element is restricted as well. For this reason, such a problem can be interpreted assuming plane strain conditions. The relationship between the matric suction change and developed horizontal stress can be determined using equation (2) (detailed derivations for equations (1) and (2) are provided in the Appendix).

$$
\sigma_{h}=\left\{\begin{array}{l}
\sigma_{x}-u_{a}=K_{0} \sigma_{s}-\frac{\Delta\left(u_{a}-u_{w}\right) E}{(1-2 v) H} \quad(\mathrm{a}), \\
\sigma_{x}-u_{a}=K_{0} \sigma_{s}^{\prime}-\frac{\Delta\left(u_{a}-u_{w}\right) E}{(1-2 v) H}+u_{w}
\end{array}\right.
$$

Equation (2)(a) can be used for scenarios in which expansive soil is still in a state of unsaturated condition (with certain suction in spite of some wetting). However, equation (2)(b) is suitable for scenarios in which expansive soil has attained saturated condition from an initial state of unsaturated condition.

\section{Passive Earth Pressure Limiting the LSP Mobilization}

The total LEP acting on retaining structures cannot exceed passive earth pressure to avoid shear failure. Liu and Vanapalli [35] proposed a series of models for the estimation of passive earth pressure for different degrees of saturation and interface roughness. The passive earth pressures for saturated soil against rough surface $\left(\sigma_{h p 1}\right)$, saturated soils against frictionless surface $\left(\sigma_{h p 2}\right)$, unsaturated soil against rough surface $\left(\sigma_{h p 3}\right)$, and unsaturated soils against 
frictionless surface $\left(\sigma_{\mathrm{hp} 4}\right)$ are given in equations (3), (4), (5), and (6), respectively.

$$
\begin{aligned}
& \sigma_{h p 1}=\sigma_{s} \frac{1+\sin \varphi^{\prime} \cos 2 \alpha_{p}}{1-\sin \varphi^{\prime} \cos 2 \alpha_{p}}+c^{\prime} \frac{2 \cos \varphi^{\prime} \cos 2 \alpha_{p}}{1-\sin \varphi^{\prime} \cos 2 \alpha_{p}}+p_{0}, \\
& \sigma_{h p 2}=\frac{\sigma_{s}\left(1+\sin \varphi^{\prime}\right)}{1-\sin \varphi^{\prime}}+\frac{2 c^{\prime} \cos \varphi^{\prime}}{1-\sin \varphi^{\prime}} \\
& \sigma_{h p 3}=\sigma_{s} \frac{1+\sin \varphi^{\prime} \cos 2 \alpha_{p}}{1-\sin \varphi^{\prime} \cos 2 \alpha_{p}}+\left[c^{\prime}+\left(u_{a f}-u_{w f}\right) \tan \varphi^{b}\right] \frac{2 \cos \varphi^{\prime} \cos 2 \alpha_{p}}{1-\sin \varphi^{\prime} \cos 2 \alpha_{p}}, \\
& \alpha_{p}=\frac{1}{2} \arcsin \frac{C}{\sqrt{A^{2}+B^{2}}}-\frac{1}{2} \arctan \frac{B}{A} \text {, } \\
& \left\{\begin{array}{l}
A=\sigma_{s} \sin \varphi^{\prime}+\left[c^{\prime}+\left(u_{a f}-u_{w f}\right) \tan \varphi^{b}\right] \cos \varphi^{\prime}, \\
B=\left[c_{a}^{\prime}+\left(u_{a f}-u_{w f}\right) \tan \delta^{b}\right] \sin \varphi^{\prime}-\sigma_{s} \sin \varphi^{\prime} \tan \delta^{\prime}-2\left[c^{\prime}+\left(u_{a f}-u_{w f}\right) \tan \varphi^{b}\right] \cos \varphi^{\prime} \tan \delta^{\prime}, \\
C=\sigma_{s} \tan \delta^{\prime}+\left[c_{a}^{\prime}+\left(u_{a f}-u_{w f}\right) \tan \delta^{b}\right],
\end{array}\right. \\
& \sigma_{h p 4}=\frac{\sigma_{s}\left(1+\sin \varphi^{\prime}\right)}{1-\sin \varphi^{\prime}}+\frac{2\left[c^{\prime}+\left(u_{a f}-u_{w f}\right) \tan \varphi^{b}\right] \cos \varphi^{\prime}}{1-\sin \varphi^{\prime}}
\end{aligned}
$$

where $\sigma_{s}$ is the vertical stress due to self-weight of upper soil layers and surcharge; $p_{0}$ is the pore water pressure; $c$ ' is the true cohesion of soil; $c_{a}^{\prime}$ is the interface cohesion; $\phi^{\prime}$ is the effective internal friction angle of soil; $\phi^{b}$ is the angle of friction with respect to matric suction; $\delta^{\prime}$ is the interface friction angle with respect to net normal stress; $\delta^{b}$ is the interface friction angle with respect to matric suction; and $\left(u_{a f}-u_{w f}\right)$ is the matric suction on the failure plane at failure.

\section{Time Effect and Fatigue Phenomenon}

Time effect and fatigue also influence the mobilization of LSP. Time effects are typically determined from both the laboratory and in situ tests. The swelling pressure increases rapidly due to water infiltration, reaches a peak value, and decreases gradually to a stable final value $[5,37,38]$. The mobilization of LSP within an expansive backfill can be divided into four stages in a chronological order based on experimental data acquired from laboratory and large-scale pilot tests: (i) in the first stage, LEP initially arises due to the influence soil self-weight over a certain depth after placement or burial; compaction can also contribute to the LEP to some extent depending on the compaction energy used. However, this influence is not significant until the compaction pressures reduce the void ratio (e) of the compacted backfill to a value typically less than 0.15 ; (ii) in the second stage, soil softening phenomenon leads to a slight decrease in the LEP after compaction at constant moisture content; (iii) in the third stage, water intrusion induced volume expansion will lead to a further increase in LEP to the maximum value under a constant vertical stress; (iv) finally, in the fourth stage, LEP reduces gradually with time due to soil softening at saturated water content. The changing pattern of LEP after soil volume expansion shows good agreement with the statement made by Joshi and Katti [4]: initial increase occurs quickly to a maximum value and then decreases slightly and finally remains at an almost constant value. Saba et al. [12] concluded that such a behavior could be attributed to changes in the microstructure and collapse of macrostructure.

Meanwhile, cyclic wetting and drying associated with environmental factors can significantly influence the mechanical behavior of expansive soils. The swelling ability of a typical expansive soil starts decreasing after a certain number of wetting and drying cycles $[39,40]$. This behavior is usually defined as fatigue phenomenon. Investigation studies of some investigators suggest that predominant swelling or shrinkage occurs during the first wetting and drying cycle [41, 42]. However, volume change behavior significantly reduces after four or five wetting and drying cycles to attain equilibrium conditions. Al-Homoud et al. [41] monitored the variation in soil structure during wetting and drying cycles with the help of a microscope and revealed that clay aggregates show weaker orientation in this process due to the integration of soil structure along the bedding. In other words, destruction of large aggregates and disorientation of structural elements continue until a turbulent flocculated soil structure is formed. Due to this reason, the ability of the expansive soil to imbibe and swell reduces significantly. 


\section{Example Problem}

In order to illustrate the proposed theoretical framework and highlight the influence of vertical boundary effects and the LSP, an example problem is discussed assuming a typical basement wall for a residential structure and a pile foundation for a multistoried structure is constructed in Regina clay from Saskatchewan province in Canada, which is a typical expansive soil. The difficulties associated with the Regina expansive clay in engineering practice warrant the need to study the influence of LSP on geotechnical infrastructures.

Figure 4(a) shows key details of a multistoried structure which is supported by pile foundation and Figure 4(c) highlights basement details for a typical residential structure. Details related to Figure 4(b) are discussed later in this section. Canadian Foundation Engineering Manual (CFEM) [43] recommends providing crawl space to alleviate with problems associated with ground heave and vertical swelling pressure on the light structures constructed on expansive soils. However, in order to highlight the influence of LSP, it is assumed in this example problem that there is no crawl space provided between the ground surface and the foundation. The CFEM [43] does not provide recommendations or methods for determining the LSP or offer design guidelines.

Between the two adjacent structures, shown in Figures 4(a) and 4(c), it is assumed there is natural ground terrain with some vegetation that prevents development of cracks but facilitates water infiltration. For realistic analyses of the example problem, soil suction profiles are assumed uniformly distributed within the active zone of $3 \mathrm{~m}$. The two values of matric suction (i.e., $361 \mathrm{kPa}$ and $44 \mathrm{kPa}$ as shown in Figure 4(b)) used in this example problem were obtained by $\mathrm{Vu}$ and Fredlund [44], who investigated volume change behavior associated with the heave of a floor slab of a light industrial building in north-central Regina, Saskatchewan. Comprehensive details of the test site and related monitoring programs for suction measurements were presented by Yoshida et al. [45].

Initially, a uniformly distributed matric suction of $361 \mathrm{kPa}$ along the entire depth of active zone of $3 \mathrm{~m}$ is assumed, which reflects drought conditions. Two different scenarios are analyzed in this problem: the first one (Scenario I) assumes that, after precipitation, rainwater infiltrates into the soil through the developed roots system and contributes to a matric suction decrease to $44 \mathrm{kPa}$. In other words, this scenario suggests the soil is still in an unsaturated state during the final phase. The second one (Scenario II) assumes significant precipitation that leads to saturation condition of the expansive soil within the active zone.

Information of various soil properties of Regina clay summarized in Table 1 was obtained from [44]. Shear strength properties were collected from another project conducted by [43] on Regina clay, as this information is not available in [44].

Based on the experimental study presented by [46], it is assumed the interface shear strength parameters were $60 \%$ of soil shear strength parameters, as given in Table 2. Parameter sensitivity analysis is also conducted in order to study the influence of soil strength and interface roughness on the development of LEP and passive earth pressure under different boundary conditions.

In addition to the shear strength parameters, three elastic parameters, namely, elastic modulus with respect to net normal stress, $E$, elastic modulus with respect to matric suction, $H$, and Poisson's ratio $v$, are necessary. $\mathrm{Vu}$ and Fredlund [44] presented equation (7) for the calculation of the elastic modulus with respect to net normal stress according to the results derived from constant volume oedometer swelling pressure test results for Regina clay. Similarly, using the data from the same test, the elastic modulus with respect to matric suction can be written as equation (8) [44]. Poisson's ratio is assumed constant and is calculated from $K_{0}$ according to (9) [44].

$$
E=28.11\left(\sigma_{\text {ave }}-u_{a}\right)
$$

where $\sigma_{\mathrm{ave}}=0.5\left(\sigma_{x}+\sigma_{y}\right)$ for plain strain loading.

$$
\begin{aligned}
H & =140.5\left(u_{a}-u_{w}\right), \\
v & =\frac{K_{0}}{1+K_{0}} .
\end{aligned}
$$

Figure 5 illustrates the development of LEP against the basement wall and around the pile for both Scenarios I and II. For both scenarios, the LEP against the basement wall calculated using equation (1) has a value higher than at-rest earth pressure due to the influence of LSP. However, it should be noted that LEP is lower than the passive earth pressure condition. The LEP around a pile calculated using equation (2) has a value higher than the basement wall. This is because of the assumption that the ground heave is restrained, which promotes the mobilization of LSP. For Scenario II, the development of LEP is limited by the passive earth pressure for rough interface within a certain depth. In comparison with Scenario I that reflects partially saturated condition, higher LEP is generated for Scenario II, under fully saturated soil conditions. This is because a greater suction reduction can contribute to a higher LSP. In addition, the passive earth pressure against smooth surface is always higher than rough surface. In addition, the passive earth pressure for unsaturated state for Scenario I is higher than that for Scenario II, which is saturated state. The results illustrated in Figure 5 are consistent with the expected mechanical behavior as well.

Figures 6 and 7 highlight the influence of shear strength parameters (SSP) on the development of the LEP against the basement wall and around the pile for different scenarios. In order to highlight the differences associated with changes in the SSP for different scenarios, percentage changes in LEPs are summarized and compared with the initial values. Table 3 summarizes the average percentage increases or decreases of LEP within the active zone depth of $3 \mathrm{~m}$ for different scenarios. The mobilization of LEP against the basement wall and surrounding the pile slightly reduces with increasing values in the SSP. However, passive earth pressure keeps increasing with an increase in SSP values. The LEP 


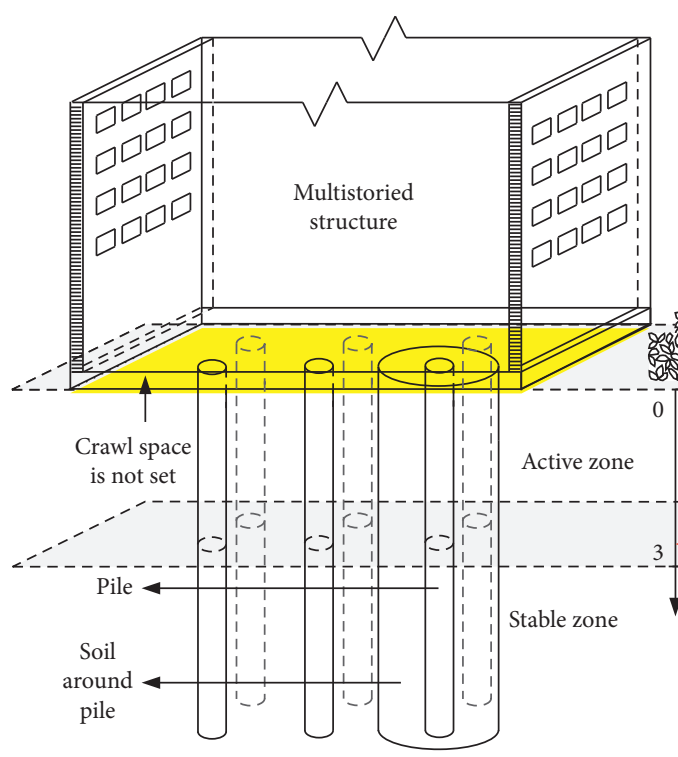

(a)

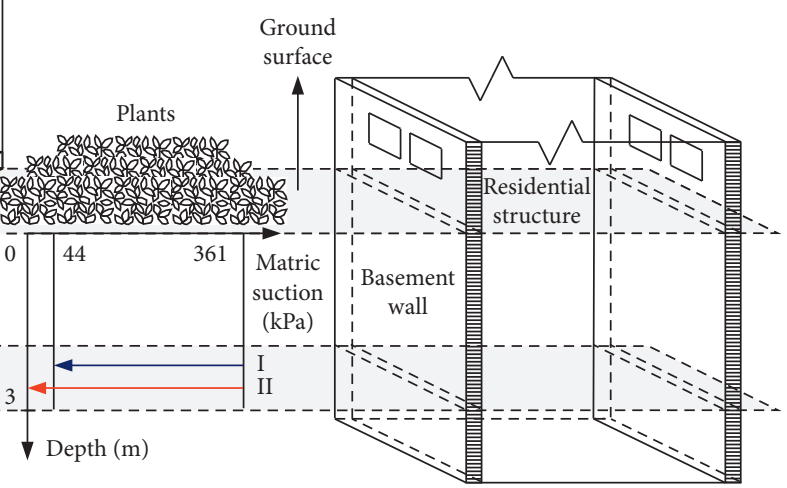

(b) (c)

FIGURE 4: Sketch of the case study on the mobilization of LSP against basement wall and around the pile: (a) pile foundation; (b) suction variations in the active zone; (c) basement wall.

Table 1: Basic properties of Regina clay (from [44]).

Liquid limit, LL (\%)

Plastic limit, PL (\%)

Plastic index, PI

Specific gravity, G

TABLE 2: Strength parameters of Regina clay and soil-structure interface.

\begin{tabular}{lccccc}
\hline & $\begin{array}{c}\text { Original properties } \\
\text { (from [43]) }\end{array}$ & $\begin{array}{c}\text { Soil parameters } \\
\text { increase 10\% }\end{array}$ & $\begin{array}{c}\text { Soil parameters } \\
\text { decrease 10\% }\end{array}$ & $\begin{array}{c}\text { Interface parameters } \\
\text { increase } 10 \%\end{array}$ & $\begin{array}{c}\text { Interface parameters } \\
\text { increase } 10 \%\end{array}$ \\
\hline $\begin{array}{l}\text { Soil internal friction angle with } \\
\text { respect to net normal stress, } \phi^{\prime}\left(^{\circ}\right)\end{array}$ & 27.9 & 30.7 & 25.1 & 27.9 & 27.9 \\
$\begin{array}{l}\text { Soil internal friction angle with } \\
\text { respect to matric suction, } \phi^{b}\left({ }^{\circ}\right)\end{array}$ & 19.8 & 21.8 & 17.8 & 19.8 & 19.8 \\
$\begin{array}{l}\text { Interface friction angle with } \\
\text { respect to net normal stress, } \delta^{\prime}\left({ }^{\circ}\right)\end{array}$ & 16.7 & 17.9 & 14.7 & 16.7 & 18.4 \\
$\begin{array}{l}\text { Interface friction angle with } \\
\text { respect to matric suction, } \delta^{b}\left({ }^{\circ}\right)\end{array}$ & 11.9 & 11.9 & 11.9 & 16.7 \\
$\begin{array}{l}\text { True soil cohesion, } c^{\prime}(\mathrm{kPa}) \\
\text { True interface cohesion, } c_{a}^{\prime}(\mathrm{kPa})\end{array}$ & 16.3 & 16.3 & 16.3 & 13.1 & 10.8 \\
\hline
\end{tabular}




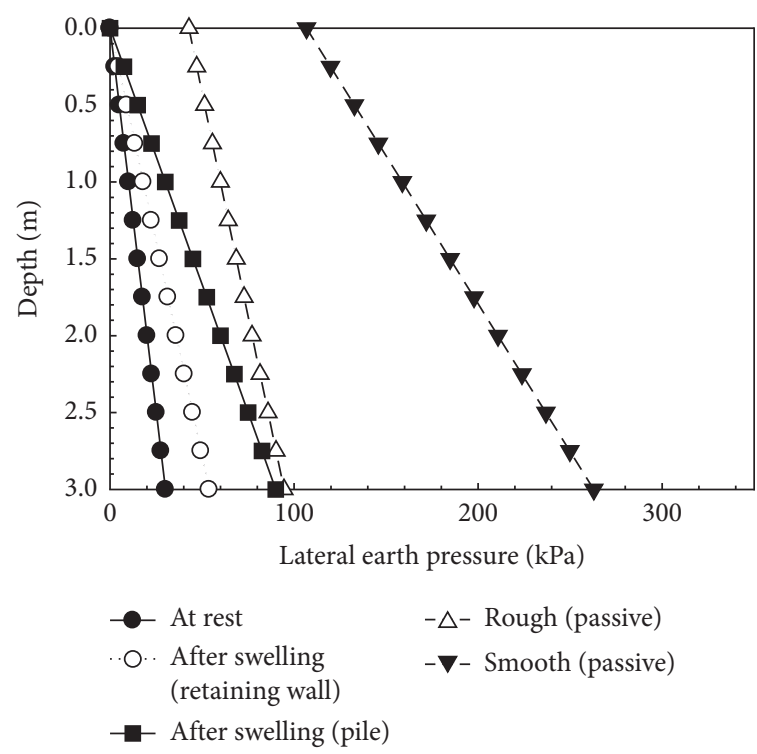

(a)

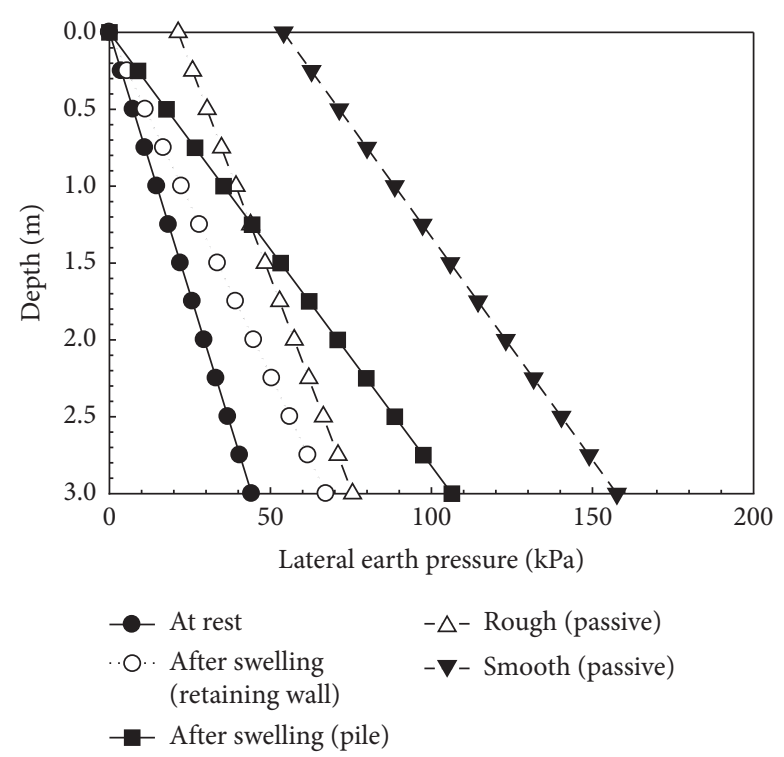

(b)

FIGURE 5: Development of LEP against basement wall. (a) Unsaturated condition and (b) saturated condition.

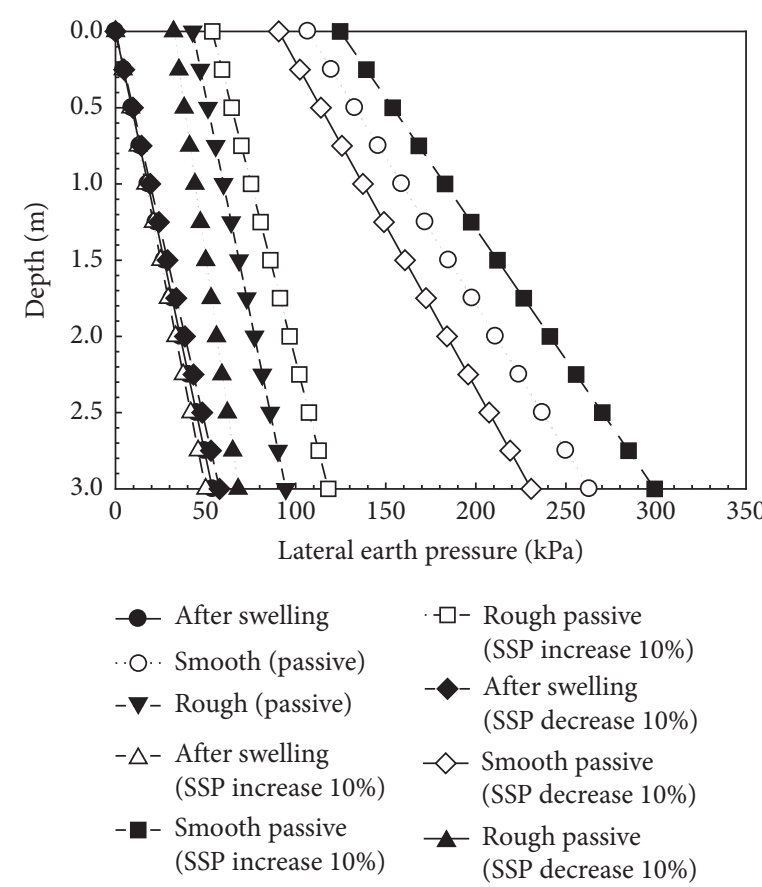

(a)

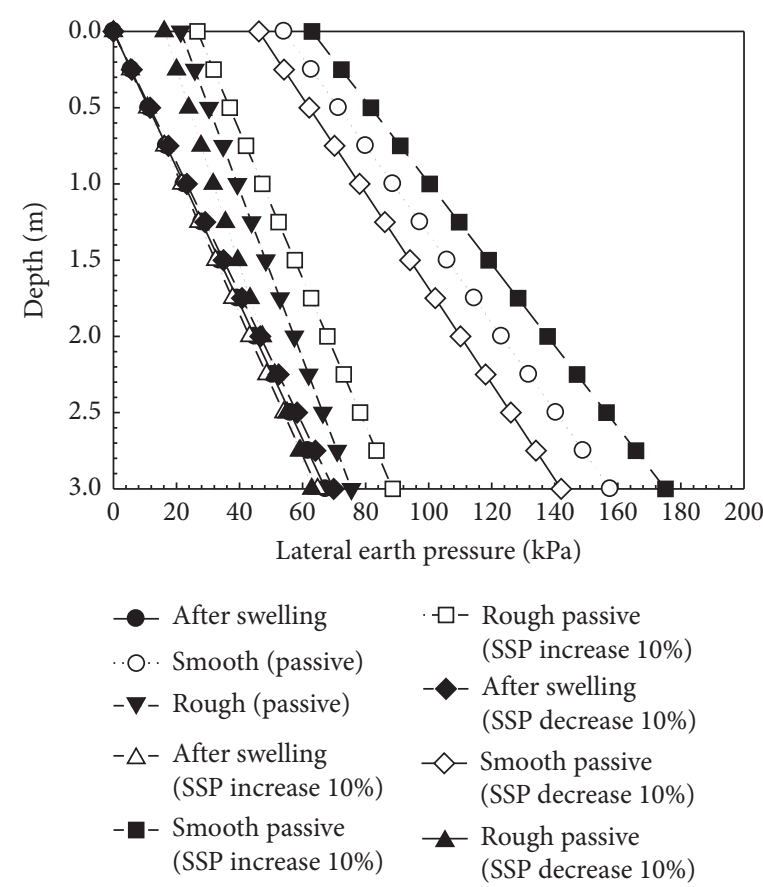

(b)

Figure 6: Development of LEP against basement wall for different shear strength properties of the soil. (a) Unsaturated condition and (b) saturated condition.

around the pile is more sensitive to the changes in SSP compared with basement wall because of the vertical heave restriction. For both the basement wall and pile, the changes in SSP pose significant influence on the passive earth pressure compared with LEP after swelling.

Figure 8 presents the influence of interface roughness on the passive earth pressure against the basement wall and around the pile for different situations. Table 4 summarizes the average percentage changes of passive earth pressure within the active zone depth of $3 \mathrm{~m}$ for different conditions (i.e., saturated and unsaturated). The results suggest that a lower passive earth pressure would arise for a structure with a rougher interface for both the saturated and unsaturated conditions. In addition, the influence of LSP changes on passive earth pressure in unsaturated state is more pronounced than the saturated state. 


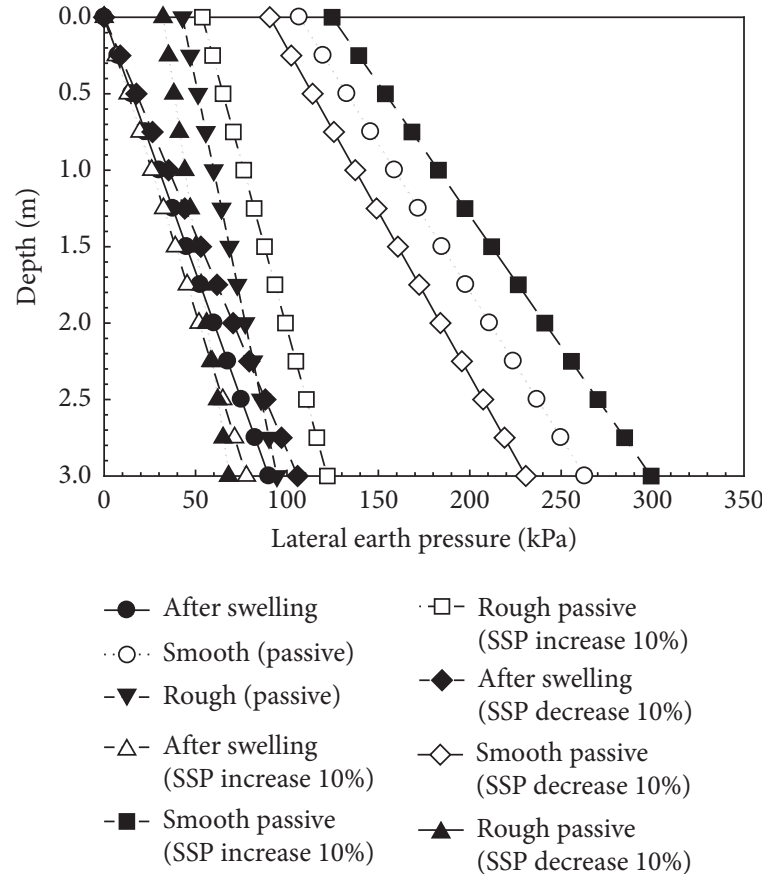

(a)

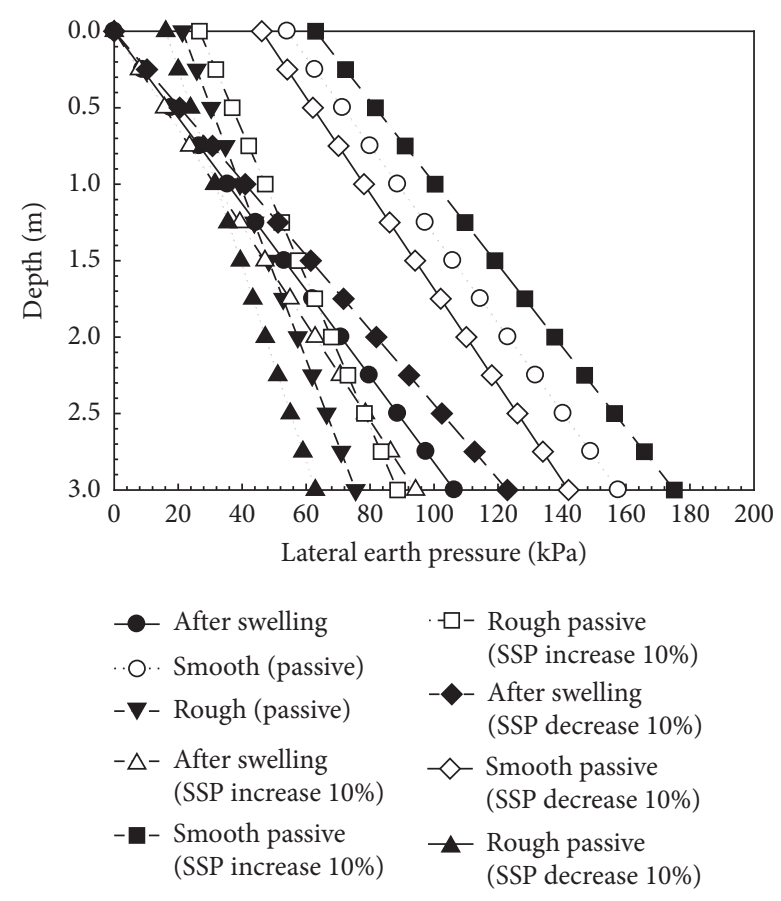

(b)

FIGURE 7: Development of LEP around pile for different shear strength properties of the soil. (a) Unsaturated condition and (b) saturated condition.

TABLE 3: Average percentage variations of LEP within active zone depth in different situations.

\begin{tabular}{llcccc}
\hline \multirow{2}{*}{ Different situations } & & \multicolumn{4}{c}{ LEP changes in percentage (\%) } \\
& & After swelling (basement wall) & After swelling (pile) & Smooth (passive) & Rough (passive) \\
\hline \multirow{2}{*}{ Unsaturated condition } & SSP increase 10\% & -7.03 & -13.62 & 14.94 & 25.27 \\
& SSP decrease 10\% & 7.30 & 17.56 & -13.29 & -26.76 \\
\hline \multirow{2}{*}{ Saturated condition } & SSP increase 10\% & -3.72 & -11.40 & 12.89 & 19.67 \\
& SSP decrease 10\% & 3.89 & 15.57 & -11.55 & -19.17 \\
\hline
\end{tabular}

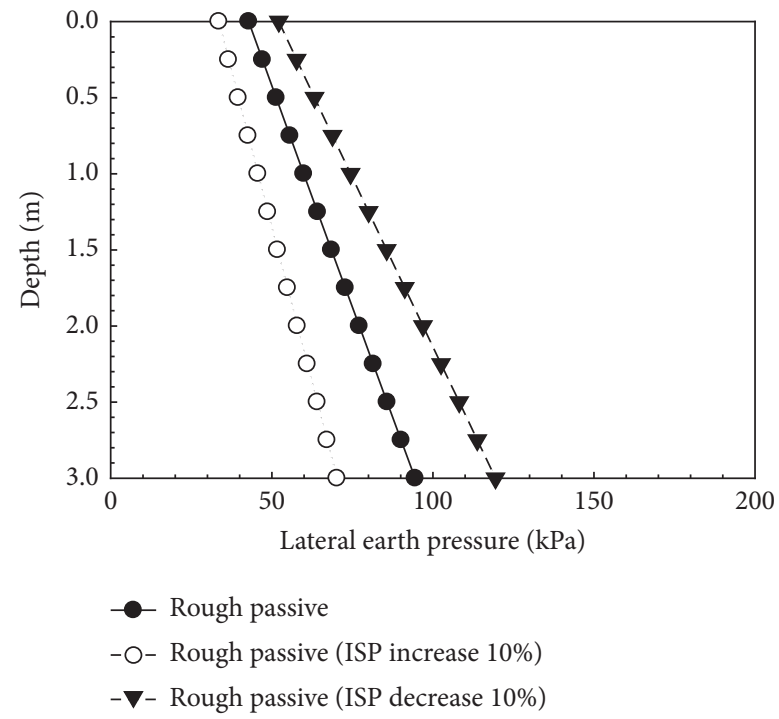

(a)

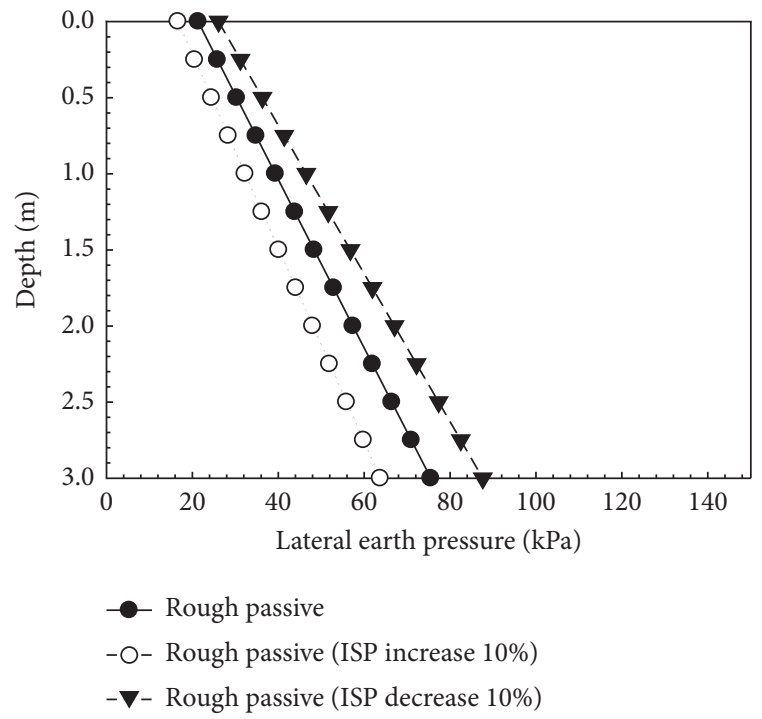

(b)

FIGURE 8: Development of passive earth pressure against basement wall and around the pile for different interface roughness. (a) Unsaturated condition and (b) saturated condition. 
TABLE 4: Percentage variations of passive earth pressure within active zone depth in different situations.

\begin{tabular}{llc}
\hline & & $\begin{array}{c}\text { Changes in } \\
\text { percentage (\%) }\end{array}$ \\
\hline Unsaturated condition & ISP increase 10\% & 24.68 \\
Saturated condition & ISP decrease 10\% & -24.14 \\
\hline
\end{tabular}

\section{Conclusions}

Mobilization of lateral swelling pressure (LSP) triggered by water infiltration can contribute to serious damages to geoinfrastructure constructed in expansive soils. For this reason, LSP should be considered as a key factor that greatly influences the design and construction of geotechnical infrastructure. In this paper, various factors that influence the mobilization of LSP are summarized in a flowchart. Then a theoretical framework extending mechanics of unsaturated soils is presented taking account of influence of the LSP for the rational design of retaining walls and pile foundations for expansive soils. This framework has been extended on example problems to highlight their application in conventional engineering practice.

Swelling pressure that mobilizes and acts on geotechnical infrastructure can be attributed to water infiltration in expansive soils that triggers swelling potential. Swelling potential is conventionally determined or estimated from the information of clay content, clay minerals, or clay structure in expansive soils. Clay particle orientation is a key factor that influences the swelling pressure both in vertical and in horizontal directions. Particle orientation is determined by the stress path in natural soils and the compaction method in remoulded soils. In addition, both the time effects and fatigue phenomenon have significant impact on the mobilization of LSP. Such a behavior can be more reliably derived from large-scale model and in situ tests.

The lateral earth pressure (LEP) against geotechnical infrastructure changes within a range between active and passive states due to seasonal wetting and drying effects. The LEP that is generated considering the mobilization of LSP typically has a higher value in comparison to at-rest earth pressure condition. This value increases with an increase in the degree of saturation of the soil. Restricted ground heave greatly promotes the mobilization of LSP but increasing shear strength parameters inhibit its mobilization. The passive earth pressure in an expansive soil that is in a state of unsaturated condition is always higher than that of saturated state. The passive earth pressure increases with increasing soil strength but decreases with an increasing interface roughness.

\section{Appendix}

\section{A. Calculation of LEP against Retaining Walls considering LSP Extending Elastic Theory}

The LEP acting against geotechnical structures considering LSP within elastic range extending soil structure constitutive relationships in terms of stress state variables, namely, matric suction and net normal stress as proposed by [36], is shown in the following equation:

$$
\left\{\begin{array}{l}
\varepsilon_{x}=\frac{\left(\sigma_{x}-u_{a}\right)}{E}-\frac{v}{E}\left(\sigma_{y}+\sigma_{z}-2 u_{a}\right)+\frac{\left(u_{a}-u_{w}\right)}{H}, \\
\varepsilon_{x}=\frac{\left(\sigma_{x}-u_{a}\right)}{E}-\frac{v}{E}\left(\sigma_{y}+\sigma_{z}-2 u_{a}\right)+\frac{\left(u_{a}-u_{w}\right)}{H}, \\
\varepsilon_{y}=\frac{\left(\sigma_{y}-u_{a}\right)}{E}-\frac{v}{E}\left(\sigma_{x}+\sigma_{z}-2 u_{a}\right)+\frac{\left(u_{a}-u_{w}\right)}{H}, \\
\gamma_{x y}=\frac{\tau_{x y}}{G}, \\
\gamma_{y z}=\frac{\tau_{y z}}{G} \\
\gamma_{z x}=\frac{\tau_{z x}}{G}
\end{array}\right.
$$

where $\left(\sigma_{x}-u_{a}\right)$ is the net normal stress in $x$ direction; $\left(\sigma_{y}-u_{a}\right)$ is the net normal stress in $y$ direction; $\left(\sigma_{z}-u_{a}\right)$ is the net normal stress in $z$ direction; $\left(u_{a}-u_{w}\right)$ is matric suction; $E$ is the elastic modulus with respect to net normal stress; $\tau_{x y}$ is the shear stress on the $x$-plane in the $y$ direction (i.e., 
$\left.\tau_{x y}=\tau_{y x}\right) ; \tau_{y z}$ is the shear stress on the $y$-plane in the $z$ direction (i.e., $\tau_{y z}=\tau_{z y}$ ); $\tau_{z x}$ is the shear stress on the $\mathrm{z}$-plane in the $x$ direction (i.e., $\tau_{z x}=\tau_{x z}$ ); $H$ is the elastic modulus with respect to matric suction; $G$ is shear modulus; and $v$ is Poisson's ratio.

The constitutive relationship for soil structure can be simplified as plane strain problem as equation (A.2) (as discussed earlier using Figure 3(a)). With a decrease in matric suction, the soil element has a tendency to expand in both $x$ and $y$ directions. Expansion in $x$ direction is restricted due to the influence of boundary condition and expansion in $y$ direction is influenced by a vertical stress (i.e., due to soil self-weight and/or surcharge). The relationship between the decreased matric suction and developed horizontal stress is given in equation (A.3). By replacing the term $(v / 1-v)\left(\sigma_{y}-u_{a}\right)$ in equation (A.3), which represents the LEP due to soil self-weight and/or surcharge, a more rigorous calculation is possible considering both saturated and unsaturated conditions appearing in the final phase is given as equation (A.4).

$$
\left\{\begin{array}{l}
\varepsilon_{x}=\frac{\left(1-v^{2}\right)}{E}\left[\left(\sigma_{x}-u_{a}\right)-\frac{v}{1-v}\left(\sigma_{y}-u_{a}\right)\right]+(1+v) \frac{\Delta\left(u_{a}-u_{w}\right)}{H}, \\
\varepsilon_{y}=\frac{\left(1-v^{2}\right)}{E}\left[\left(\sigma_{y}-u_{a}\right)-\frac{v}{1-v}\left(\sigma_{x}-u_{a}\right)\right]+(1+v) \frac{\Delta\left(u_{a}-u_{w}\right)}{H}, \\
\tau_{x y}=\frac{E \gamma_{x y}}{2(1+v)},
\end{array}\right.
$$

$$
\sigma_{h}=\sigma_{x}-u_{a}=\frac{v}{1-v}\left(\sigma_{y}-u_{a}\right)-\frac{\Delta\left(u_{a}-u_{w}\right) E}{(1-v) H}
$$$$
\sigma_{h}=\left\{\begin{array}{l}
\sigma_{x}-u_{a}=K_{0} \sigma_{s}-\frac{\Delta\left(u_{a}-u_{w}\right) E}{(1-v) H} \quad(\mathrm{a}), \\
\sigma_{x}-u_{a}=K_{0} \sigma_{s}^{\prime}-\frac{\Delta\left(u_{a}-u_{w}\right) E}{(1-v) H}+u_{w}
\end{array}\right.
$$

In equation (A.3), where $\Delta\left(u_{a}-u_{w}\right)$ is matric suction increment, (a) is suitable for scenarios in which expansive soil has not been fully saturated after suction variation while (b) is suitable for scenarios in which expansive soil has been fully saturated after suction variation.

\section{B. Calculation of the LEP Mobilized on Piles considering LSP Extending Elastic Theory}

For piles inserted in expansive soils (as shown in Figure 3(b)), the soil around the pile can be assumed as a hollow cylinder with inner diameter $a$ and external diameter $b$ ( $b$ is infinite). With a decrease in matric suction, the hollow cylinder tends to expand in both axial and radial directions. However, boundary conditions restrict both the inner and external expansion. Assuming the vertical expansion of the soil element is restricted due to the influence of load, this problem can be simplified to be a plane strain problem. Neglecting the body force, the equations for equilibrium, geometric, and constitutive relationship for soil cylinder are, respectively, given in equations (B.1), (B.2), and (B.3).

$$
\left\{\begin{array}{l}
\frac{\partial\left(\sigma_{r}-u_{a}\right)}{\partial r}+\frac{1}{r} \frac{\partial \tau_{\phi r}}{\partial \phi}+\frac{\sigma_{r}-\sigma_{\phi}}{r}=0 \\
\frac{1}{r} \frac{\partial\left(\sigma_{\phi}-u_{a}\right)}{\partial \phi}+\frac{\partial \tau_{r \phi}}{\partial r}+\frac{2 \tau_{r \phi}}{r}=0
\end{array}\right.
$$

where $\left(\sigma_{r}-u_{a}\right)$ is the net normal stress in radial direction; $\left(\sigma_{\varphi}-u_{a}\right)$ is the net normal stress in circumferential direction; $\tau_{\varphi r}$ is circumferential strain; $\tau_{r \varphi}$ is radial strain; $r$ is the distance from the center of the pile.

$$
\left\{\begin{array}{l}
\varepsilon_{r}=\frac{\partial u_{r}}{\partial r}, \\
\varepsilon_{\phi}=\frac{u_{r}}{r}+\frac{1}{r} \frac{\partial u_{\phi}}{\partial \phi}, \\
\gamma_{r \phi}=\frac{1}{r} \frac{\partial u_{r}}{\partial \phi}+\frac{\partial u_{\phi}}{\partial r}-\frac{u_{\phi}}{r}
\end{array}\right.
$$

where $u_{r}$ is radial displacement and $u_{\varphi}$ is circumferential displacement.

$$
\left\{\begin{array}{l}
\varepsilon_{r}=\frac{1-v^{2}}{E}\left[\left(\sigma_{r}-u_{a}\right)-\frac{v}{1-v}\left(\sigma_{\phi}-u_{a}\right)\right]+\frac{(1+v) \Delta\left(u_{a}-u_{w}\right)}{H} \\
\varepsilon_{\phi}=\frac{1-v^{2}}{E}\left[\left(\sigma_{\phi}-u_{a}\right)-\frac{v}{1-v}\left(\sigma_{r}-u_{a}\right)\right]+\frac{(1+v) \Delta\left(u_{a}-u_{w}\right)}{H} \\
\gamma_{r \phi}=\frac{\tau_{r \phi}}{G}
\end{array}\right.
$$


Considering that there is only a change in the matric suction, the above three equations can be simplified as equations (B.3), (B.4), and (B.5), correspondingly.

$$
\begin{aligned}
& \frac{\partial\left(\sigma_{r}-u_{a}\right)}{\partial r}+\frac{\sigma_{r}-\sigma_{\phi}}{r}=0, \\
& \left\{\begin{array}{l}
\varepsilon_{r}=\frac{\partial u_{r}}{\partial r} \\
\varepsilon_{\phi}=\frac{u_{r}}{r}
\end{array}\right. \\
& \left\{\begin{array}{l}
\varepsilon_{r}=\frac{1-v^{2}}{E}\left[\left(\sigma_{r}-u_{a}\right)-\frac{v}{1-v}\left(\sigma_{\phi}-u_{a}\right)\right]+\frac{(1+v) \Delta\left(u_{a}-u_{w}\right)}{H}, \\
\varepsilon_{\phi}=\frac{1-v^{2}}{E}\left[\left(\sigma_{\phi}-u_{a}\right)-\frac{v}{1-v}\left(\sigma_{r}-u_{a}\right)\right]+\frac{(1+v) \Delta\left(u_{a}-u_{w}\right)}{H} .
\end{array}\right.
\end{aligned}
$$

Rearranging equation (B.6), the axial stress and radial stress can be expressed in terms of axial and radial strain as shown in equation (B.7). Then, by substituting equations
(B.4) and (B.5) into equation (B.7), equation (B.8) can be obtained.

$$
\left\{\begin{array}{l}
\left(\sigma_{r}-u_{a}\right)=\frac{E}{1-v} \frac{1-v}{1-2 v}\left(\varepsilon_{r}+\frac{v}{1-v} \varepsilon_{\phi}\right)-\frac{E}{H} \frac{u_{a}-u_{w}}{1-2 v}, \\
\left(\sigma_{\phi}-u_{a}\right)=\frac{E}{1-v} \frac{1-v}{1-2 v}\left(\varepsilon_{\phi}+\frac{v}{1-v} \varepsilon_{r}\right)-\frac{E}{H} \frac{u_{a}-u_{w}}{1-2 v}, \\
\frac{d^{2} u_{r}}{d r^{2}}+\frac{1}{r} \frac{d u_{r}}{d r}-\frac{u_{r}}{r^{2}}=\frac{1+v}{(1-v) H} \frac{d \Delta\left(u_{a}-u_{w}\right)}{d r} .
\end{array}\right.
$$

The expression for axial displacement can be obtained as summarized in equation (B.8) by carrying out two integrations on equation (B.8):

$$
u_{r}=\frac{(1+v)}{(1-v) H r} \int_{a}^{r} \Delta\left(u_{a}-u_{w}\right) r \mathrm{~d} r+c_{1} r+\frac{c_{2}}{r} \text {. }
$$

Using equation (B.9), a link is built connecting the axial displacement with axial and radial stress, which is given as

$$
\left\{\begin{array}{l}
\left(\sigma_{r}-u_{a}\right)=-\frac{E}{H r^{2}(1-v)} \int_{a}^{r} \Delta\left(u_{a}-u_{w}\right) r \mathrm{~d} r+\frac{E(1-v)}{(1+v)(1-2 v)}\left(\frac{c_{1}}{1-v}-\frac{1-2 v}{1-v} \frac{c_{2}}{r^{2}}\right) \\
\left(\sigma_{\phi}-u_{a}\right)=\frac{E}{H r^{2}(1-v)} \int_{a}^{r} \Delta\left(u_{a}-u_{w}\right) r \mathrm{~d} r+\frac{E(1-v)}{(1+v)(1-2 v)}\left(\frac{c_{1}}{1-v}-\frac{1-2 v}{1-v} \frac{c_{2}}{r^{2}}\right)-\frac{E}{(1-v) H} \Delta\left(u_{a}-u_{w}\right) .
\end{array}\right.
$$

In equation (B.10), $c_{1}$ and $c_{2}$ are determined from boundary conditions. The values of $c_{1}$ and $c_{2}$ can be acquired by substituting equation (B.11) into equation (B.9) extending the assumption that both the internal and external displacement boundary conditions are restricted (equation (B.11)):

$$
\begin{aligned}
& \left\{\begin{array}{l}
u_{r a}=0, \\
u_{r b}=0,
\end{array}\right. \\
& \left\{\begin{array}{l}
c_{1}=-\frac{(1+v) \Delta\left(u_{a}-u_{w}\right)}{2 H(1-v)}, \\
c_{2}=\frac{(1+v) \Delta\left(u_{a}-u_{w}\right)}{2 H(1-v)} a^{2} .
\end{array}\right.
\end{aligned}
$$

The axial stress acting on the inner diameter can be calculated using equation (B.13), which is obtained by substituting the value of $c_{1}$ and $c_{2}$ from equation (B.12) into equation (B.10):

$$
\sigma_{x}-u_{a}=\frac{-\Delta\left(u_{a}-u_{w}\right) E}{(2 v-1) H}
$$

Finally, the total LEP acting on the pile can be calculated using equation (B.14) that includes the LEP due to soil selfweight and surcharge (adding the body force which is ignored in the previous analysis by superposition method) to equation (B.13). Similar to analysis conducted for LEP against retaining walls, theoretical elastic equations are developed for calculation of LEP around the pile considering both saturated and unsaturated condition in the final phase as equation (B.15):

$$
\begin{aligned}
& \sigma_{h}=\sigma_{x}-u_{a}=-\frac{\Delta\left(u_{a}-u_{w}\right) E}{(1-2 v) H}, \\
& \sigma_{h}=\left\{\begin{array}{l}
\sigma_{x}-u_{a}=K_{0} \sigma_{s}-\frac{\Delta\left(u_{a}-u_{w}\right) E}{(1-2 v) H} \quad \text { (a), } \\
\sigma_{x}-u_{a}=K_{0} \sigma_{s}^{\prime}-\frac{\Delta\left(u_{a}-u_{w}\right) E}{(1-2 v) H}+u_{w}
\end{array}\right.
\end{aligned}
$$

Equation (B.15) (a) is suitable for scenarios in which expansive soil has not been fully saturated after suction variation; however, equation (B.15) (b) is suitable for scenario in which expansive soil is fully saturated (i.e., suction is lost due to wetting associated with infiltration of water).

\section{Data Availability}

The data used to support the findings of this study are available from the corresponding author upon request. 


\section{Conflicts of Interest}

The authors declare that they have no conflicts of interest.

\section{References}

[1] B. G. Richards and M. Kurzeme, "Observations of earth pressures on a retaining wall at Gouger street mail exchange, adelaide," Australian Geomechanics Journal, vol. G3, no. 1, pp. 21-26, 1973.

[2] R. Lytton, "Design of structures to resist the pressures and movements of expansive soils" Ph.D. Thesis, Texas A\&M University, College Station, TX, USA, 2007.

[3] K. K. Moza, R. K. Katti, and D. R. Katti, "Active pressure studies in saturated expansive soil," in Proceedings of the Eighth Asian Regional Conference on Soil Mechanics and Foundation Engineering, pp. 189-192, Kyoto, Japan, 1987.

[4] R. P. Joshi and R. K. Katti, "Lateral pressure development under surcharges," in Proceedings of the 4th Intemational Conference on expansive soils, pp. 227-241, Denver, CO, USA, 1980.

[5] O. Z. Mohamed, Y. K. Taha, and E.-S. M. A. El-Aziz, "Field study of the distribution of lateral swelling pressure of expansive soil on retaining structure," JES. Journal of Engineering Sciences, vol. 42, no. 2, pp. 289-302, 2014.

[6] C. W. W. Ng, L. T. Zhan, C. G. Bao, D. G. Fredlund, and B. W. Gong, "Performance of an unsaturated expansive soil slope subjected to artificial rainfall infiltration," Géotechnique, vol. 53, no. 2, pp. 143-157, 2003.

[7] F. H. Chen, Foundations on Expansive Soils, Elsevier Scientific Publishing Co., Amsterdam, Netherlands, 1988.

[8] R. W. Day, "Swell-shrink behavior of compacted clay," Journal of Geotechnical Engineering, vol. 120, no. 3, pp. 618623, 1994.

[9] H. H. Adem and S. K. Vanapalli, "Heave prediction in a natural unsaturated expansive soil deposit under a lightly loaded structure," Geotechnical and Geological Engineering, vol. 34, no. 4, pp. 1181-1192, 2016.

[10] A. J. Puppala and A. Cerato, "Heave distress problems in chemically-treated sulfate-laden materials," Geo-Strata, vol. 10, no. 2, pp. 28-30, 2009.

[11] S. Azam and G. W. Wilson, "Volume change behavior of a fissured expansive clay containing anhydrous calcium sulfate," Unsaturated Soils, pp. 906-915, 2006.

[12] S. Saba, J.-D. Barnichon, Y.-J. Cui, A. M. Tang, and P. Delage, "Microstructure and anisotropic swelling behaviour of compacted bentonite/sand mixture," Journal of Rock Mechanics and Geotechnical Engineering, vol. 6, no. 2, pp. 126132, 2014.

[13] Y. Xie, Z. H. Chen, S. G. Sun, G. Li, and X. W. Fang, "Test research on three-dimensional swelling pressure of remolded expansive clay," Rock and Soil Mechanics, vol. 28, no. 8, pp. 1636-1642, 2007, in Chinese.

[14] S. B. Ikizler, M. Vekli, E. Dogan, M. Aytekin, and F. Kocabas, "Prediction of swelling pressures of expansive soils using soft computing methods," Neural Computing and Applications, vol. 24 , no. 2, pp. 1-13, 2012.

[15] R. K. Katti, E. S. Bhangle, and K. K. Moza, "Lateral pressure of expansive soil with and without a cohesive non-swelling soil layer applications to earth pressures of cross drainage structures of canals and key walls of dams (studies of K0 condition)," Technical Report 32, Central Board of Irrigation and Power, New Delhi, India, 1983.
[16] X. W. Gu, "Study on the interaction between unsaturated expansive soils and structure," M.S. thesis, Nanjing Hydraulic Research Institute, Nanjing, China, 2005, in Chinese.

[17] H. Nagaraj, M. Munnas, and A. Sridharan, "Swelling behavior of expansive soils," International Journal of Geotechnical Engineering, vol. 4, no. 1, pp. 99-110, 2010.

[18] T. Schanz and Y. Al-Badran, "Swelling pressure characteristics of compacted Chinese Gaomiaozi bentonite GMZ01," Soils and Foundations, vol. 54, no. 4, pp. 748-759, 2014.

[19] J. D. Nelson, K. C. Chao, D. D. Overton, and E. J. Nelson, Foundation Engineering for Expansive Soils, John Wiley \& Sons, Hoboken, NJ, USA, 2015.

[20] J. D. Nelson and D. J. Miller, Expansive Soils, Problems and Practice in Foundation and Pavement Engineering, John Wiley \& Sons, New York, NY, USA, 1992.

[21] J. D. Nelson, D. D. Overton, and D. B. Durkee, "Depth of wetting and the active zone. Expansive clay soils and vegetative influence on shallow foundations," ASCE Geotechnical Special Publications, vol. 116, pp. 95-109, 2001.

[22] A. R. Estabragh, M. Moghadas, and A. A. Javadi, "Effect of different types of wetting fluids on the behaviour of expansive soil during wetting and drying," Soils and Foundations, vol. 53, no. 5, pp. 617-627, 2013.

[23] H. B. Nagaraj, M. Munnas, and A. Sriharan, "Critical evaluation of determining swelling pressure by swell-load method and constant volume method," Geotechnical Testing Journal, ASTM, vol. 32, no. 4, pp. 1-10, 2009.

[24] ASTM (American Society for Testing and Materials), Standard Test Methods for One-Dimensional Swell or Collapse of Soils. ASTM D4546 - 14, ASTM International, West Conshohocken, PA, USA, 2014.

[25] D. Mašín and N. Khalili, "Swelling phenomena and effective stress in compacted expansive clays," Canadian Geotechnical Journal, vol. 53, no. 1, pp. 134-147, 2016.

[26] R. N. Yong, "Soil suction and soil-water potentials in swelling clays in engineered clay barriers," Engineering Geology, vol. 54, no. 1-2, pp. 3-13, 1999.

[27] H.-J. Herbert and H. C. Moog, "Modelling of saturation and swelling effects in clays under different saline conditions," in Proceedings of the Eurosafe Forum 2000, Seminar 4, Waste Management, Germany, 2000.

[28] R. Pusch, "Mechanical properties of clays and clay minerals," in Handbook of Clay Science, F. Bergaya, B. K. G. Theng, and G. Lagaly, Eds., vol. 1, pp. 247-260, Elsevier, Amsterdam, Netherlands, 2006.

[29] A. Sridharan, A. S. Rao, and P. V. Sivapullaiah, "Swelling pressure of clays," Geotechnical Testing Journal, vol. 9, no. 1, pp. 24-33, 1986.

[30] R. K. Katti, D. R. Katti, and A. R. Katti, Behavior of Saturated Expansive Soil and Control Methods, Revised and Enlarged Edition, Balkema, Amsterdam, The Netherlands, 2002.

[31] H. Liu, A. Deng, and J. Chu, "Effect of different mixing ratios of polystyrene pre-puff beads and cement on the mechanical behaviour of lightweight fill," Geotextiles and Geomembranes, vol. 24, no. 6, pp. 331-338, 2006.

[32] S. B. Ikizler, M. Aytekin, and E. Nas, "Laboratory study of expanded polystyrene (EPS) geofoam used with expansive soils," Geotextiles and Geomembranes, vol. 26, no. 2, pp. 189-195, 2008.

[33] A. P. Shelke and D. S. Murty, "Reduction of swelling pressure of expansive soils using EPS geofoam," in Proceedings of the Indian Geotechnical Conference, pp. 495-498, IIT Mumbai, Powai, Mumbai, December 2010. 
[34] M. A. Al-Shamrani and A. W. Dhowian, "Experimental study of lateral restraint effects on the potential heave of expansive soils," Engineering Geology, vol. 69, no. 1-2, pp. 63-81, 2003.

[35] Y. Liu and S. K. Vanapalli, "Influence of lateral swelling pressure on the geotechnical infrastructure in expansive soils," Journal of Geotechnical and Geoenvironmental Engineering, vol. 143, no. 6, Article ID 04017006, 2017.

[36] D. G. Fredlund and H. Rahardjo, Unsaturated Soil Mechanics in Engineering Practice, John Wiley \& Sons, New Jersey, NJ, USA, 2002.

[37] C. R. I. Clayton, I. F. Symons, and J. C. Hiedra-Cobo, "The pressure of clay backfill against retaining structures," Canadian Geotechnical Journal, vol. 28, no. 2, pp. 282-297, 1991.

[38] I. F. Symons and C. R. I. Clayton, "Earth pressures on backfilled retaining walls," Ground Engineering, pp. 26-34, 1992.

[39] A. E. Dif and W. F. Bluemel, "Expansive soils under cyclic drying and wetting," Geotechnical Testing Journal, Technical Note, vol. 14, no. 1, pp. 96-102, 1991.

[40] A. R. Estabragh, B. Parsaei, and A. A. Javadi, "Laboratory investigation of the effect of cyclic wetting and drying on the behaviour of an expansive soil," Soils and Foundations, vol. 55, no. 2, pp. 304-314, 2015.

[41] A. S. Al-Homoud, A. A. Basma, A. I. Husein Malkawi, and M. A. Al Bashabsheh, "Cyclic swelling behavior of clays," Journal of Geotechnical Engineering, vol. 121, no. 7, pp. 562$565,1995$.

[42] A. A. Basma, A. S. Al-Homould, M. Husein, and M. A. AiBashabsheh, "Swelling-shrinkage behavior of natural expansive clays," Applied Clay Science, vol. 11, no. 2-4, pp. 211-277, 1996.

[43] Canadian Geotechnical Society, Canadian Foundation Engineering Manual, Canadian Geotechnical Society, 4th edition, 2006.

[44] H. Q. Vu and D. G. Fredlund, "The prediction of one, twoand three-dimensional heave in expansive soils," Canadian Geotechnical Journal, vol. 4, pp. 1-25, 2004.

[45] R. T. Yoshida, D. G. Fredlund, and J. J. Hamilton, "The prediction of total heave of a slab-on-grade floor on Regina clay," Canadian Geotechnical Journal, vol. 20, no. 1, pp. 69-81, 1983.

[46] T. B. Hamid and G. A. Miller, "Shear strength of unsaturated soil interfaces," Canadian Geotechnical Journal, vol. 46, no. 5, pp. 595-606, 2009. 